\title{
Contamination, persistence and dissemination of Cronobacter during the production of powdered infant formula in China in 2016
}

\author{
Xin Gan', Baowei Yang ${ }^{2}$, Xiaofei Wang ${ }^{1}$, Yinping Dong1, Yujie Hu${ }^{1}$, Jin Xu' ${ }^{1}$, Fengqin Li ${ }^{1, *}$ \\ ${ }^{1}$ Key Laboratory of Food Safety Risk Assessment, Ministry of Health, China National Center for Food Safety Risk \\ Assessment, Beijing 100021, P. R. China; ${ }^{2}$ College of Food Science and Engineering, Northwest AEF University, Yangling, \\ China
}

*Corresponding Author: Fengqin Li, Key Laboratory of Food Safety Risk Assessment, Ministry of Health, China National Center for Food Safety Risk Assessment, Beijing 100021, P. R. China. Email: lifengqin@cfsa.net.cn

Received: 15 November 2020. Accepted: 17 December 2020. Published 15 February 2021. (C) 2021 Codon Publications

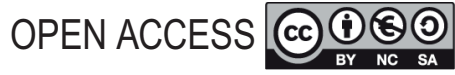

RESEARCH ARTICLE

\begin{abstract}
A total of 620 samples collected from two factories in China producing powdered infant formula (PIF) between July and November 2016 were analyzed for Cronobacter. Antimicrobial susceptibility, pulsed-field gel electrophoresis (PFGE), and biofilm formation of Cronobacter were carried out. The results showed that 2.26\% samples were positive for Cronobacter among the 33 isolates that were identified. All Cronobacter isolates were susceptible to 12 antimicrobial agents tested except one isolate which showed intermediate resistance to Chloramphenicol. PFGE analysis showed that nine clusters comprising the 33 isolates were identified, among which C8, C4, and C5 were the predominant types. All 33 isolates were capable of forming biofilm, and particularly, C. malonaticus isolates showed a good biofilm-forming ability at both $28^{\circ} \mathrm{C}$ and $37^{\circ} \mathrm{C}$. The results illustrated that it is necessary for PIF manufactures to develop control measures for reducing Cronobacter contamination and its associated foodborne illness among infants.
\end{abstract}

Keywords: biofilm; Cronobacter; PFGE; powdered infant formula

\section{Introduction}

Cronobacter spp. (formerly Enterobacter sakazakii) are Gram-negative opportunistic pathogens but fatal in neonates and immunocompromised infants (Ling et al., 2018). The genus Cronobacter currently comprises seven species: C. sakazakii, C. dublinensis, C. turicensis, C. malonaticus, C. muytjensii, C. condiment, and C. universalis. It is well known that Cronobacter had been classified as pathogenic organisms to a restricted population, especially causing life-threatening infections in neonates and immunocompromised infants (Forsythe, 2018). These organisms are widely distributed in foods including powdered infant formulas (PIF), infant cereal foods, dairy products, fruits, and elements in the environment like soil, water, and dust (Tutar et al., 2018; Ueda, 2017). Cronobacter infections in infants occur mostly through the consumption of contaminated PIF. As a non-sterile product, PIF is a major source of nutrition for infants under 6 months of age who could not be breastfed; however, the production of PIF involves stages where the product is susceptible to microbial, especially Cronobacter contamination, the most vulnerable phase occurring after pasteurization and prior to packaging (Drapala et al., 2018; Kalyantanda et al., 2015; Pires et al., 2020). In several outbreaks caused by Cronobacter, the source of infection was traced to contaminated PIF or to spoons and blenders used in preparation of PIF (Chenu and Cox, 2009; Friedemann, 2008). Additionally, Cronobacter spp. display remarkable resistance to 
desiccation compared with other Enterobacteriaceae, which may contribute to their long-term survival in PIF and on surfaces of the production environment (Gurtler and Beuchat, 2007). Cronobacter contamination can occur in any step during PIF production, especially in raw ingredients, during processing-originating from the surrounding environment, as a result of improper flushing, and in the prepared PIF for infant consumption. Besides, multiple studies illustrated that some strains of Cronobacter are able to form biofilms on glass, stainless steel, polyvinyl chloride, polycarbonate, silicone, and enteral feeding tubes through different media (Henry and Monica, 2019; Iversen et al., 2004). Biofilm formation by Cronobacter species is a major concern to the PIF industry, as biofilms on raw ingredients or PIF contact surfaces represent possible sources of product contamination with Cronobacter.

Our previous study showed that four $(3.4 \%, 4 / 119)$ out of 119 retailed powdered formula samples collected from 16 provinces between 2014 and 2015 were positive for Cronobacter (Gan et al., 2018). Based on this result, we carried out a 5-month successive surveillance for Cronobacter along the entire PIF production chain in two PIF manufactures of which their PIF at retail level were contaminated by Cronobacter. The aim of this study was to determine the Cronobacter contamination pathways, to characterize the antimicrobial susceptibility as well as biofilm formation of the major species of Cronobacter recovered in these two factories. Meanwhile, pulsed-field gel electrophoresis (PFGE) of Cronobacter isolating from different origins was also conducted in order to track the source of contamination across the entire PIF production chain.

\section{Materials and Methods}

\section{Sample collection}

Two factories (referred to as A and B) located in Shan $\mathrm{Xi}$ province, China were chosen to carry out a 5-month surveillance from July to November 2016. Sampling plan was set up based on production flow of dry process. A total of 620 samples including 174 powder samples, 33 liquid samples, 135 air sedimentation samples, and 278 swab samples were obtained from 54 sampling areas and items including raw ingredients, surface of equipment, environment (soil and dust), swabs of the staff's hand, intermediate products, the end products etc. Among them, 195 samples including 28 powder samples, six liquid samples, 48 air sedimentation samples, and 113 swab samples were collected from Factory A. While, 425 samples including 146 powder samples, 27 liquid samples, 87 air sedimentation samples and 165 swab samples were obtained from Factory B. Brain Heart Agar (BHA) plates were used to collect air samples. Briefly, plates were exposed in the air in different areas of PIF production for 15-20 min. Additionally, $50 \mathrm{~mL}$ sterile centrifuge tubes were used to collect liquid samples including raw goat milk, concentrated milk, and water; they were collected from production pipeline. Powder samples including base powder, final PIF powder, soil around factory, floor powder, and raw ingredients were collected at amounts shown in Table 1 and stored in sampling bags. Swab samples were collected over a $25 \mathrm{~cm}^{2}$ surface with sterile cotton swabs moistened in buffered peptone water (BPW). Details were given in Table 1. All samples were placed in insulation box with ice bag and tested on the same day.

\section{Isolation and species identification of Cronobacter}

Samples were detected for Cronobacter using a modified method based on China National Food Safety Standard (GB4789.40, 2016). For powder and liquid samples, an aliquot of $100 \mathrm{~g}$ (or) $\mathrm{mL}$ test portion was mixed with $900 \mathrm{~mL}$ BPW (unless otherwise indicated, all media from Beijing Land Bridge Technology Ltd., Beijing, China) and incubated at $37^{\circ} \mathrm{C}$ for $18 \mathrm{~h} \pm 2 \mathrm{~h}$. Swabs were inoculated into $10 \mathrm{~mL} \mathrm{BPW}$ and incubated at $37^{\circ} \mathrm{C}$ for $18 \mathrm{~h} \pm 2 \mathrm{~h}$. The pre-enrichment samples were mixed well followed by transferring $1 \mathrm{~mL}$ into a tube containing $10 \mathrm{~mL} \mathrm{mLST} /$ Vancomycin medium and incubated at $41.5^{\circ} \mathrm{C}$ for $24 \mathrm{~h} \pm 2 \mathrm{~h}$. A loop full of $\mathrm{mLST} /$ vancomycin culture was streaked on Brilliance Enterobacter sakazakii Agar (DFI) (Oxoid, England), and incubated at $41.5^{\circ} \mathrm{C}$ for $24 \mathrm{~h} \pm 2 \mathrm{~h}$. Five suspected colonies (all suspected colonies would be picked up when the number of colonies less than five) were selected and inoculated onto tryptone soya agar (TSA) plate and incubated at $37^{\circ} \mathrm{C}$ for $24 \mathrm{~h}$. Colonies on TSA plate were further identified by both VITEK $^{\ominus} 2$ Compact (bioMérieux, France) and ITS (ITS-F 5'-GGGTTGTCTGCGAAAGCGAA-3', ITS-R 5'-GTCTTCGTGCTGCGAGTTTG-3') by polymerase chain reaction (PCR) based on the method published by Liu (Liu et al., 2006). During determination of Cronobacter in the air of PIF production areas by disk sedimentation on TSA plate, all plates were incubated at $25^{\circ} \mathrm{C}$ for $48 \mathrm{~h} \pm 4 \mathrm{~h}$. Yellow pigment colonies were selected and streaked on TSA plate again and identified by both VITEK ${ }^{\odot} 2$ Compact and PCR, respectively.

For Cronobacter identification at species level, seven pairs of primers designed according to RNA polymerase $\beta$ subunit $(r p o B)$ gene were used to differentiate the seven species of Cronobacter according to the methods published previously (Lehner et al., 2012; Stoop et al., 2009). A total of $25 \mu \mathrm{l}$ PCR reaction mixtures were prepared containing $12.5 \mu \mathrm{l}$ of $2 \times$ GoTaq Green Master Mix, each primer $(10 \mu \mathrm{mol} / \mathrm{L})$ for $1 \mu \mathrm{l}, 9.5 \mu \mathrm{l}$ of distilled deionized water and $1 \mu \mathrm{l}$ of template. The primer sequences and PCR conditions are shown in Table 2. 
Table 1. Distribution of samples collected from factories.

\begin{tabular}{|c|c|c|c|c|}
\hline Sample categories & Sample description & $\begin{array}{l}\text { No. of Factory A } \\
\text { samples }\end{array}$ & $\begin{array}{l}\text { No. of Factory B } \\
\text { samples }\end{array}$ & Amount \\
\hline \multirow[t]{6}{*}{ Liquid } & Raw goat milk & $N T^{*}$ & 9 & $50 \mathrm{~mL}$ \\
\hline & Concentrated milk & 3 & 9 & \\
\hline & Internal cleaning water of production pipeline & & & \\
\hline & A water sample before homogenization & 1 & 3 & \\
\hline & B water sample after sterilization & 1 & 3 & \\
\hline & C concentrated water sample after homogenization & 1 & 3 & \\
\hline \multirow[t]{18}{*}{ Powder } & Goat milk powder (base powder 0 ) & 3 & 15 & $300 \mathrm{~g}$ \\
\hline & Base powder 1 (wet processing technology) & 3 & 6 & \\
\hline & Final powder (dry processing technology) & 3 & 12 & \\
\hline & Soil around factory & 8 & 20 & \\
\hline & Floor powder of packaging room & 3 & 6 & $100 \mathrm{~g}$ \\
\hline & Whey powder & 3 & 15 & \\
\hline & Lactose & NT & 15 & \\
\hline & Concentrated whey protein & 1 & 5 & \\
\hline & Galacto-oligosaccharide & 1 & 5 & \\
\hline & Fructo oligosaccharides & NT & 5 & \\
\hline & DHA powder & NT & 5 & \\
\hline & ARA powder & NT & 5 & \\
\hline & Casein calcium phosphate & NT & 5 & \\
\hline & $\alpha$-Lactoalbmin & NT & 5 & \\
\hline & Lactorferrin & NT & 4 & \\
\hline & Bifidobacterium & NT & 12 & \\
\hline & Vegetable oil & NT & 3 & \\
\hline & Floor powder of fluid-bed workshop & 3 & 3 & \\
\hline \multirow[t]{10}{*}{ Disk sedimentation } & Release station & NT & 12 & $15-20 \mathrm{~min}$ \\
\hline & Bunker room & 6 & NT & \\
\hline & Concentration room & 6 & 9 & \\
\hline & Fluid-bed room & 6 & 9 & \\
\hline & Inside packaging room & 6 & 12 & \\
\hline & Excipients room & 6 & NT & \\
\hline & Clean area & 3 & 12 & \\
\hline & Non-clean area & 6 & 12 & \\
\hline & Air purification room & 6 & 9 & \\
\hline & Rear packaging room & 3 & 12 & \\
\hline \multirow[t]{12}{*}{ Swab } & Door handles in clean and non-clean areas & 10 & 12 & $25 \mathrm{~cm}^{2}$ \\
\hline & Excipients conveyor belt (before and after UV disinfection) & 6 & 12 & \\
\hline & Release platform & NT & 9 & \\
\hline & Entrance of mixing tank & 6 & NT & \\
\hline & Surface of mixing tank & 6 & 12 & \\
\hline & Surface of precast powder bags & 3 & 3 & \\
\hline & Fluid-bed & 6 & 6 & \\
\hline & Ground of inside packaging room & 6 & 12 & \\
\hline & Conveyor belt of inside packaging room & 6 & 12 & \\
\hline & Air vent of inside packaging room & 6 & 12 & \\
\hline & Staff's shoe soles of inside packaging room & 8 & 12 & \\
\hline & Staff's hands of inside packaging room & 6 & 12 & \\
\hline
\end{tabular}

(Continues) 
Table 1 Continued

\begin{tabular}{llcc} 
Sample categories & Sample description & $\begin{array}{c}\text { No. of Factory A } \\
\text { samples }\end{array}$ & $\begin{array}{c}\text { No. of Factory B } \\
\text { samples }\end{array}$ \\
\hline & Staff's clothes of inside packaging room & 6 & 12 \\
& Big bag packaging machine & 3 & 3 \\
Receiving sample window of rear packaging room & 3 & 12 \\
Final product conveyor belt & 3 & 12 \\
Purification system and clean room & NT & 3 \\
Air inlet of purification system & 6 & 3 \\
Air outlet & 6 & 6 \\
Drain & 7 & NT \\
Delivery window & 4 & NT \\
Entrance of preparing tank & 3 & NT \\
Outlet of preparing tank & 3 & NT
\end{tabular}

${ }^{*}$ Not tested.

Table 2 Primer sequences and PCR conditions of Cronobacter identification at species level.

\begin{tabular}{|c|c|c|c|c|c|c|c|}
\hline Species & Primer & Sequence $\left(5^{\prime} \rightarrow 3^{\prime}\right)$ & Predenaturation & denaturation & annealing & extension & $\begin{array}{l}\text { Fragment } \\
\text { size }\end{array}$ \\
\hline \multirow[t]{2}{*}{ C. condimenti } & Con-F & AAC GCC AAG CCA ATC TCG & $95 \pm 2 \min$ & $95 \pm 1 \mathrm{~min}$ & $58 \pm 30 s$ & $72 \pm 1 \mathrm{~min}$ & $689 \mathrm{bp}$ \\
\hline & Con-R & GTA CCG CCA CGT TTT GCT & & & & & \\
\hline \multirow[t]{2}{*}{ C. sakazakii } & Sak-F & ACG CCA AGC CTA TCT CCG CG & $94 \pm 3 \min$ & $94 \pm 1 \mathrm{~min}$ & $69 \pm 30 s$ & $72 \pm 1 \mathrm{~min}$ & $514 \mathrm{bp}$ \\
\hline & Sak-R & ACG GTT GGC GTC ATC GTG & & & & & \\
\hline \multirow[t]{2}{*}{ C. malonaticus } & Mal-F & CGT ATC TCT GCT CTC & $94 \pm 3 \mathrm{~min}$ & $94 \pm 1 \mathrm{~min}$ & $64 \pm 30 s$ & $72 \pm 30 s$ & $251 \mathrm{bp}$ \\
\hline & Mal-R & AGG TTG GTG TTC GCC TGA & & & & & \\
\hline \multirow[t]{2}{*}{ C. turicensis } & Tur-F & CGG TAA AAG AGT TCT TCG GC & $94 \pm 3 \min$ & $94 \pm 1 \mathrm{~min}$ & $61 \pm 30 s$ & $72 \pm 1 \mathrm{~min}$ & $628 \mathrm{bp}$ \\
\hline & Tur-R & GTA CCG CCA CGT TTC GCC & & & & & \\
\hline \multirow[t]{2}{*}{ C. dublinensis } & Dub-F & GCA CAA GCG TCG TAT CTC C & $94 \pm 3 \min$ & $94 \pm 1 \mathrm{~min}$ & $62 \pm 30 s$ & $72 \pm 30 s$ & $418 \mathrm{bp}$ \\
\hline & Dub-R & TTG GCG TCA TCG TGT TCC & & & & & \\
\hline \multirow[t]{2}{*}{ C. muytjensii } & Muy-F & TGT CCG TGT ATG CGC AGA CC & $94 \pm 3 \mathrm{~min}$ & $94 \pm 1 \mathrm{~min}$ & $67 \pm 30$ s & $72 \pm 30 s$ & $289 \mathrm{bp}$ \\
\hline & Muy-R & TGT TCG CAC CCA TCA ATG CG & & & & & \\
\hline \multirow[t]{2}{*}{ C. universalis } & Uni-F & ACA AAC GTC GTA TCT CTG CG & $94 \pm 3 \min$ & $94 \pm 1 \mathrm{~min}$ & $61 \pm 30 s$ & $72 \pm 30 s$ & 506 bp \\
\hline & Uni-R & AGC ACG TTC CAT ACC GGT C & & & & & \\
\hline
\end{tabular}

\section{Antimicrobial susceptibility testing}

Minimal inhibitory concentrations (MIC) of 12 antimicrobials including Tetracycline (TET), Nalidixic acid (NAL), Ciprofloxacin (CIP), Chloramphenicol (CHL), Sulfamethoxazole-Trimethoprim (SXT), Amoxicillin (AMX), Ampicillin (AMP), Ampicillin-Sulbactam (SAM), Gentamicin (GEN), Cefotaxime (CTX), Ceftazidime (CAZ), and Imipenem (IMP) were determined via broth microdilution method for all confirmed Cronobacter isolates. Escherichia coli ATCC 25922 was used as a quality control in antimicrobial susceptibility testing (AST) experiment. All susceptibility results were interpreted according to the Clinical and Laboratory
Standards Institute (CLSI) interpretive standards (CLSI M100S, 2016).

\section{PFGE subtyping of Cronobacter}

PFGE analysis was performed on all Cronobacter isolates. Cell suspensions were adjusted to 4-4.5 malt concentration. After solidification, plugs $[0.5 \%(\mathrm{w} / \mathrm{v})]$ were lysed in $5 \mathrm{~mL}$ cell lysis buffer $(50 \mathrm{mmol} / \mathrm{L}$ Tris- $\mathrm{HCl}, 50 \mathrm{nmol} / \mathrm{L}$ EDTA, $1 \%$ sodium lauroyl-sarcosine) and $25 \mu$ l proteinase $\mathrm{K}(20 \mathrm{mg} / \mathrm{mL})$ at $55^{\circ} \mathrm{C}$ with $170 \mathrm{r} / \mathrm{min}$ shaking for $2 \mathrm{~h}$. Plugs were washed twice with $15 \mathrm{~mL}$ deionized water for $10 \mathrm{~min}$ followed by washing with $15 \mathrm{~mL}$ TE buffer at $50^{\circ} \mathrm{C}$ 
shaking at a speed of $170 \mathrm{r} / \mathrm{min}$ for 3 times, $15 \mathrm{~min}$ for each. After cutting into $3 \mathrm{~mm}$ slices, the plug was digest with $\mathrm{XbaI}$ at $37^{\circ} \mathrm{C}$ for $2 \mathrm{~h}$. Treated plugs were cast into a $1 \%(\mathrm{w} / \mathrm{v})$ SKG gel and separated by electrophoresis in $0.5 \times$ TBE buffer at $14^{\circ} \mathrm{C}$ for $18 \mathrm{~h}$. The PFGE gel was then dyed with $0.01 \%(\mathrm{w} / \mathrm{v})$ GelRed for $30 \mathrm{~min}$ and then soaked in deionized water for $30 \mathrm{~min}$. DNA fingerprints were analyzed by BioNumerics V7.6 (Applied Math, Belgium) using DICE coefficient and unweighted pair group method with arithmetic mean (UPGMA). Patterns indistinguishable by computer and visual inspection were assigned the same pattern designation.

\section{Biofilm formation assay}

Quantification of biofilms grown in microtiter dishes was performed by following the procedure as described by Yan (Yan et al., 2015). M9 minimal medium (6 g/l $\mathrm{Na}_{2} \mathrm{HPO}_{4}, 3 \mathrm{~g} / \mathrm{l} \mathrm{KH} \mathrm{PO}_{4}, 0.5 \mathrm{~g} / \mathrm{l} \mathrm{NaCl}, 1 \mathrm{~g} / \mathrm{l} \mathrm{NH}_{4} \mathrm{Cl}, 2 \mathrm{mM}$ $\mathrm{MgSO}_{4}, 0.1 \%$ glucose and $0.1 \mathrm{mM} \mathrm{CaCl}_{2}$ ) adjusted to 0.1 Malt concentration was used as the growth medium. Cronobacter isolates were inoculated into tryptic soy broth (TSB) medium and incubated at $37^{\circ} \mathrm{C}$ overnight. Briefly, a triplicate $200 \mu \mathrm{l}$ cultures was transferred into 96-well microplates and incubated at $28^{\circ} \mathrm{C}$ and $37^{\circ} \mathrm{C}$ for $72 \mathrm{~h}$, respectively. Each well was washed with $200 \mu \mathrm{l}$ of phosphate-buffered saline (PBS) for 3 times, fixated with $200 \mu \mathrm{l}$ of methanol for $20 \mathrm{~min}$ and stained with $200 \mu \mathrm{l}$ $0.4 \%(\mathrm{w} / \mathrm{v})$ crystal violet (CV) for $15 \mathrm{~min}$ after air-drying for $15 \mathrm{~min}$. The plate was washed with $200 \mu \mathrm{l}$ PBS for 3 times, dissolved biofilm with $200 \mu \mathrm{l}$ of $33 \%$ (v/v) acetic acid for $30 \mathrm{~min}$, and measured the optical density (OD) at $570 \mathrm{~nm}$. Salmonella Typhimurium ATCC 14028 with a strong biofilm-forming capacity was selected as the positive control (Martins et al., 2013). All tests were carried out in triplicate.

\section{Results}

\section{Prevalence of Cronobacter contamination in samples}

Table 3 shows that among 620 samples, 14 (2.26\%, 14/620) were positive for Cronobacter and 33 isolates were obtained. Among the positive samples, seven (50\%, 7/14) samples were soil origin, four were swabs of drain, air inlet and soles of staff, two were PIF raw ingredients of lactose, and one was air sedimentation, respectively. In terms of 33 Cronobacter isolates, 21 (63.64\%, 21/33), seven $(21.21 \%, 7 / 33)$, four $(12.12 \%, 4 / 33)$, and one $(0.30 \%$, $1 / 33$ ) were cultured from soil, lactose, environmental swabs, and air sedimentation samples, respectively. Regarding PIF factories, 13 isolates cultured from eight samples $(57.14 \%, 8 / 14)$ including four soil samples, four swabs of air inlet of purification room, drain, and soles from Factory A and 20 isolates from six samples (42.86\%, 6/14) including three soil samples, two lactose samples and one rear packaging room air sedimentation samples from Factory B were contaminated by Cronobacter. No significant difference on the incidence of Cronobacter contamination between these two PIF factories were found (Chi-square test: $\mathrm{X}^{2}=3.251, \mathrm{P}=0.071$ ); however, contamination of raw ingredients was found in Factory B. In 14 Cronobacter positive samples, 12 samples including soil, environmental swabs, and lactose were contaminated by C. sakazakii and two (including soil and air sedimentation) by C. malonaticus, respectively. Among 33 Cronobacter isolates, C. sakazakii was the predominant species detected and accounted for $87.88 \%(29 / 33)$

Table 3 Contamination of Cronobacter monitored during PIF production.

\begin{tabular}{|c|c|c|c|c|}
\hline Factory & Sampling date & Source categories & Species & No of strains \\
\hline \multirow[t]{6}{*}{ A } & July & Soil-3 & C. sakazakii & 1 \\
\hline & & Soil-4(2) & C. sakazakii & 2 \\
\hline & & Air inlet of purification system-1 & C. sakazakii & 1 \\
\hline & & Drain-4 & C. sakazakii & 1 \\
\hline & & Staff's sole-1 & C. sakazakii & 1 \\
\hline & & Staff's sole-2 & C. sakazakii & 1 \\
\hline \multirow[t]{3}{*}{ B } & August & Lactose-1 & C. sakazakii & 4 \\
\hline & & Lactose-2 & C. sakazakii & 3 \\
\hline & & Soil-2 & C. malonaticus & 3 \\
\hline \multirow[t]{2}{*}{ A } & September & Soil-2 & C. sakazakii & 3 \\
\hline & & Soil-3 & C. sakazakii & 3 \\
\hline B & September & Soil-2 & C. sakazakii & 3 \\
\hline \multirow[t]{2}{*}{ B } & October & Disk sedimentation of rear packaging room-3 & C. malonaticus & 1 \\
\hline & & Soil-3(6) & C. sakazakii & 6 \\
\hline
\end{tabular}


followed by C. malonaticus (12.12\%, 4/33). All 13 isolates from Factory A were C. sakazakii. Whereas, 20 Cronobacter isolates from Factory B were diverse at the species level: $16(80 \%, 16 / 20)$ for C. sakazakii from soil and lactose, and four for C. malonaticus from soil and air sedimentation, respectively. Precisely, two different species were detected from soil samples collected in Factory B (Table 3).

\section{AST of Cronobacter}

Results of AST show that all 33 Cronobacter isolates cultured from different matrix samples were susceptible to all the 12 antimicrobials tested except one isolate with an intermediate resistance to Chloramphenicol.

\section{PFGE subtyping analysis}

The 33 Cronobacter isolates comprising 29 C. sakazakii and four C. malonaticus were analyzed using PFGE with $\mathrm{XbaI}$ and differentiated into nine PFGE pulsotypes with similarities above 95\% (Figure 1). The predominant pulsotype of C. sakazakii was C8, which included seven isolates (7/33, 21.2\%) cultured from lactose collected from Factory B, followed by C4 $(6 / 33,18.2 \%)$ and C5 $(6 / 33,18.2 \%)$ cultured from soil collected from Factory A and Factory B, respectively. Pulsotypes of $\mathrm{C} 3$ and $\mathrm{C} 6$ consisted of four $C$. malonaticus isolates from both soil and air sedimentation and three C. sakazakii isolates from Factory B, respectively. Three pulsotypes (C1, C2, and C7) of C. sakazakii cultured from soil, air inlet, drain, and workers' sole collected from Factory A, respectively were found to contain two isolates for each. And the remaining C9 pulsotype contained one isolate obtained from soil in Factory A. The PFGE results revealed that the drain and air inlet in the workshop of Factory A had cross contamination of Cronobacter with soil around the factory, respectively. Factory B also existed cross contamination between soil and rear packaging room environment. And the isolates collected form staff's sole of Factory A were different from other strains isolated from this factory. The contamination of Cronobacter during the production of PIF may come from both raw ingredients like lactose and the environment including soil, air, workers movement, and so forth.

\section{Biofilm formation}

All 33 Cronobacter isolates were studied for biofilm formation using the microplate method with M9 minimal medium as the growth medium at two different incubation temperatures: $28^{\circ} \mathrm{C}$ and $37^{\circ} \mathrm{C}$. A temperature of $28^{\circ} \mathrm{C}$ was chosen to simulate that of PIF processing environment, while $37^{\circ} \mathrm{C}$ was the one similar to human body temperature. Biofilm formation by Cronobacter isolates is shown in Table 4 and Figure 2. In all the 33 Cronobacter isolates tested, 17 isolates $(51.52 \%, 17 / 33)$ of C. sakazakii produced biofilm which were deemed "weak" on their rating scale with an optical density (OD) at $570 \mathrm{~nm}$ $\left(\mathrm{OD}_{570}\right)<0.2$ at both $28^{\circ} \mathrm{C}$ and $37^{\circ} \mathrm{C}$ on the basis of criteria described by Lee (Lee et al., 2012). Eight (8/33, 24.24\%) isolates including three C. malonaticus and five C. sakazakii showed intermediate capacity of biofilm formation with an $\mathrm{OD}_{570}$ ranged from 0.5 to 1.0 at $28^{\circ} \mathrm{C}$ and two of C. sakazakii isolates exhibited strong biofilm formation with an $\mathrm{OD}_{570}>1$ at $28^{\circ} \mathrm{C}$. Whereas, two $(2 / 33,6.06 \%)$ C. sakazakii and three C. malonaticus (3/33, 9.09\%) isolates showed intermediate and strong biofilm formation ability at $37^{\circ} \mathrm{C}$, respectively. No significant difference of isolates in $\mathrm{OD}_{570}>0.5$ biofilm-forming ability between $28^{\circ} \mathrm{C}$ and $37^{\circ} \mathrm{C}$ was found (Fisher test: $\mathrm{P}=0.240$ ). Additionally, intermediate and strong biofilm formation ability of four C. malonaticus isolates at $28^{\circ} \mathrm{C}$ and $37^{\circ} \mathrm{C}$, respectively, was observed. No significant difference in the biofilm-forming capacity at $28^{\circ} \mathrm{C}$ was found between C. malonaticus and C. sakazakii isolates (Fisher test: $\mathrm{P}=$ 0.073). Whereas, the capacity of 3 C. malonaticus isolates in forming biofilm at $37^{\circ} \mathrm{C}$ was significantly stronger than those of C. sakazakii (Fisher test: $\mathrm{P}=0.007$ ). Regarding the effect of temperature on biofilm formation, Figure 2 revealed that there is no significant difference in biofilm formation by Cronobacter between $28^{\circ} \mathrm{C}$ and $37^{\circ} \mathrm{C}$ (T tested: $\mathrm{P}=0.176$ ). Compared with S. Typhimurium ATCC 14028, 11 Cronobacter isolates were of stronger capacity in biofilm formation at $37^{\circ} \mathrm{C}$.

\section{Discussion}

The results of this study indicated that Cronobacter can enter processing plants through raw ingredients, soil, and PIF production environment and be disseminated throughout, especially in the situation of areas of high foot traffic were contaminated by staff's soles with Cronobacter, and consequently can cross-contaminate processing equipment and persist for long periods in these facilities. This persistence is also attributable to biofilms - a well-known factor for protecting bacteria from harsh environmental stresses such as desiccation, antimicrobials, and disinfectants-which is of concern to public health and food safety. The result of PFGE in this study further illustrated that carry-over of Cronobacter from raw ingredient as well as PIF processing environment contamination by this bacterium are the major sources of Cronobacter contamination in PIF. Therefore, PIF manufactures should strengthen the management of raw ingredients and production environments, especially they should pay more attention to external and internal environment contamination of PIF processing workshop. 


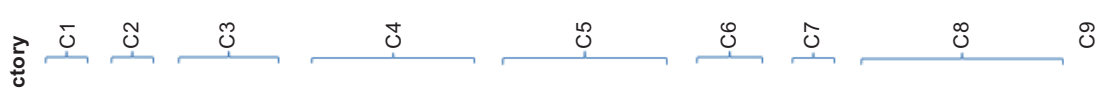

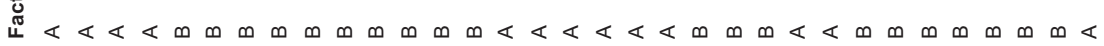

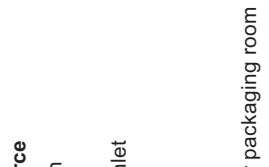

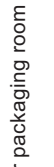

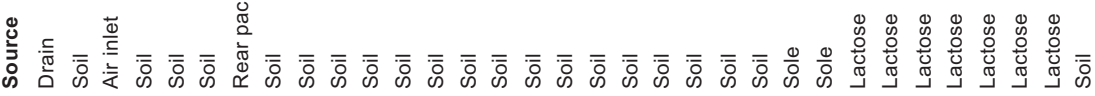

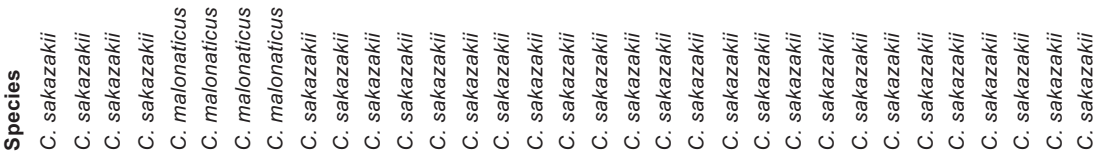

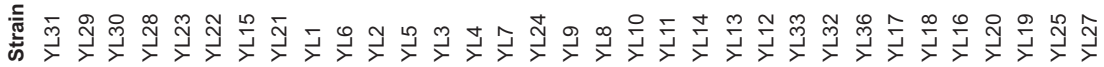

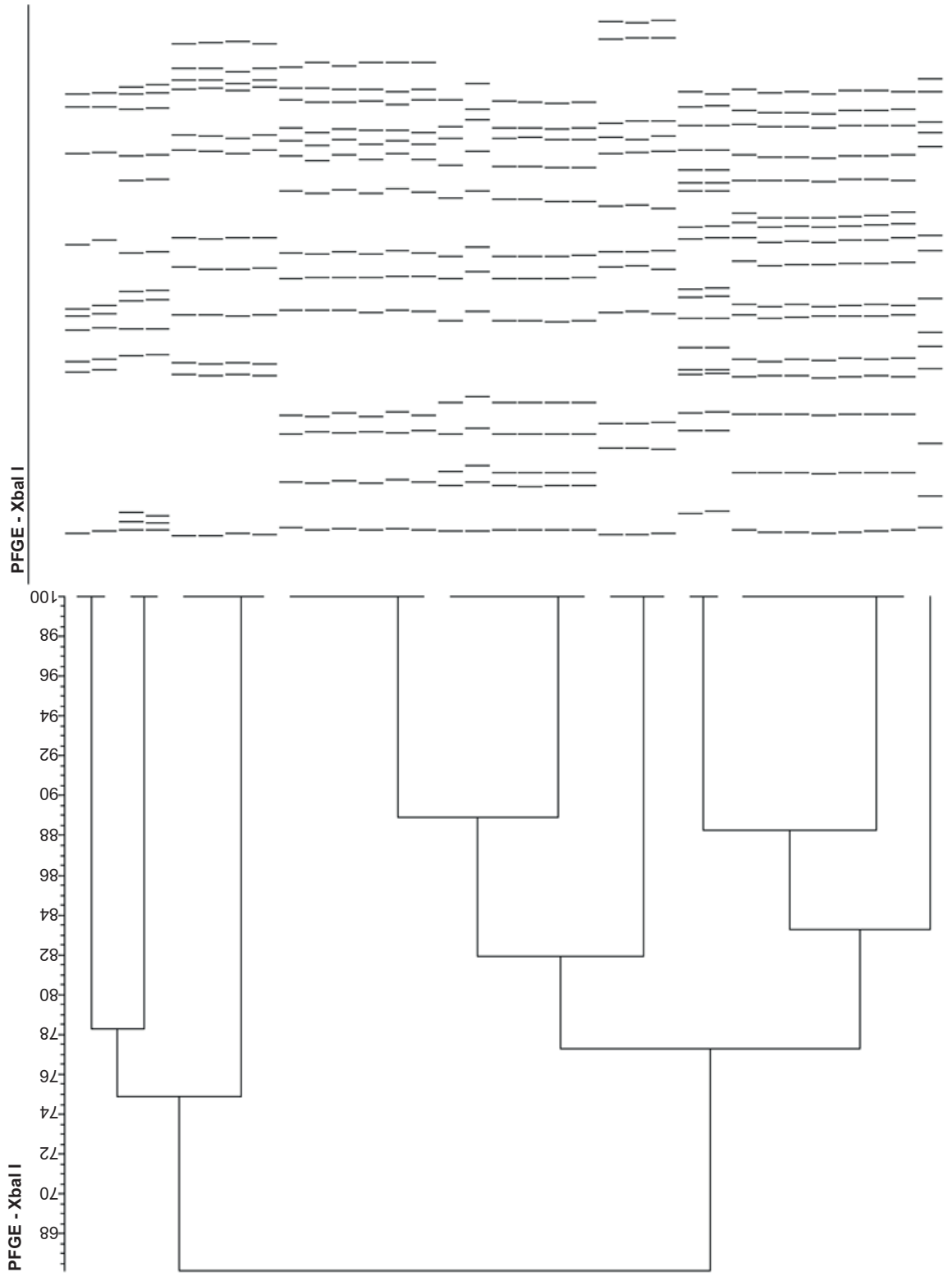

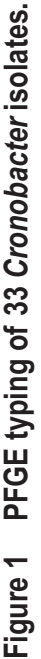


Table 4 Biofilm formation by Cronobacter expressed as $\mathrm{OD}_{570 \mathrm{~nm}}$ at different temperatures.

\begin{tabular}{|c|c|c|c|}
\hline \multirow[t]{2}{*}{ Strain ID } & \multirow[t]{2}{*}{ Species } & \multicolumn{2}{|c|}{$\begin{array}{c}\mathrm{OD}_{570 \mathrm{~nm}} \text { at different } \\
\text { temperatures }\end{array}$} \\
\hline & & $28^{\circ} \mathrm{C}$ & $37^{\circ} \mathrm{C}$ \\
\hline YL1 & C. sakazakii & 0.097 & 0.072 \\
\hline YL2 & C. sakazakii & 0.108 & 0.091 \\
\hline YL3 & C. sakazakii & 0.092 & 0.114 \\
\hline YL4 & C. sakazakii & 0.095 & 0.109 \\
\hline YL5 & C. sakazakii & 0.121 & 0.117 \\
\hline YL6 & C. sakazakii & 0.113 & 0.112 \\
\hline YL7 & C. sakazakii & 0.090 & 0.128 \\
\hline YL8 & C. sakazakii & 0.178 & 0.108 \\
\hline YL9 & C. sakazakii & 0.182 & 0.178 \\
\hline YL10 & C. sakazakii & 0.092 & 0.115 \\
\hline YL11 & C. sakazakii & 0.226 & 0.146 \\
\hline YL12 & C. sakazakii & 0.100 & 0.076 \\
\hline YL13 & C. sakazakii & 0.114 & 0.078 \\
\hline YL14 & C. sakazakii & 0.166 & 0.080 \\
\hline YL15 & C. malonaticus & 0.517 & 0.436 \\
\hline YL16 & C. sakazakii & 0.749 & 0.392 \\
\hline YL17 & C. sakazakii & 0.430 & 0.631 \\
\hline YL18 & C. sakazakii & 0.161 & 0.199 \\
\hline YL19 & C. sakazakii & 0.740 & 0.531 \\
\hline YL20 & C. sakazakii & 0.745 & 0.436 \\
\hline YL21 & C. malonaticus & 0.633 & 1.097 \\
\hline YL22 & C. malonaticus & 0.486 & 1.025 \\
\hline YL23 & C. malonaticus & 0.694 & 1.288 \\
\hline YL24 & C. sakazakii & 0.386 & 0.134 \\
\hline YL25 & C. sakazakii & 0.596 & 0.289 \\
\hline YL26 & C. sakazakii & 0.552 & 0.419 \\
\hline YL27 & C. sakazakii & 0.338 & 0.204 \\
\hline YL28 & C. sakazakii & 0.095 & 0.113 \\
\hline YL29 & C. sakazakii & 0.138 & 0.049 \\
\hline YL30 & C. sakazakii & 0.103 & 0.118 \\
\hline YL31 & C. sakazakii & 0.467 & 0.204 \\
\hline YL32 & C. sakazakii & 1.043 & 0.352 \\
\hline YL33 & C. sakazakii & 1.203 & 0.459 \\
\hline 14028 & $\begin{array}{l}\text { Salmonella } \\
\text { Typhimurium }\end{array}$ & 1.891 & 0.298 \\
\hline
\end{tabular}

Among the 33 Cronobacter isolates, 29 (87.88\%, 29/33) were C. sakazakii and four $(12.12 \%, 4 / 33)$ were C. malonaticus. C. sakazakii is the dominant species isolated, which was the same as previous studies (Fei et al., 2015, 2017). Since all seven species of Cronobacter have pathogenicity and the clinical reports of neonatal Cronobacter infection are primarily because of C. sakazakii, C. malonaticus, and C. turicensis. According to Stephen J. Forsythe, grouped Cronobacter species were divided into two groups: Group 1 comprises C. sakazakii and C. malonaticus as the majority of clinical isolates in all age groups. C. sakazakii is mainly related to neonatal infections while $C$. malonaticus is related to adult infections (Forsythe, 2018; Jaradat et al., 2014). Hence, we can speculate that infants who consumed PIF produced by these two factories that is contaminated with one or more Cronobacters like C. sakazakii and $C$. malonaticus would be at a high risk of Cronobacter infection on the basis of our study.

Antibiotic resistant bacteria has been the focus of global attention; the spread of antibiotic resistant bacteria directly leads to the reduction or ineffectiveness of clinical antibiotic treatments, extend patient's course, and could cause complications. All the 33 Cronobacter isolates obtained in the present study were susceptible to all 12 antimicrobials tested except one isolate that was of intermediate resistance to Chloramphenicol. Our previous studies revealed that eight out of 417 (1.92\%) Cronobacter isolates cultured from four kinds of infant foods from 27 provinces in China during 2012-2014 were resistant to antimicrobials, including AMX (3), AMP (2), CHL (2), CTX (1), NAL (1), SXT (1), and TET (1) (Gan et al., 2015). These data imply that Cronobacter isolates were generally sensitive to antimicrobials, similar to the results reported by Gu, Chen and Pei (Chen et al., 2011; Gu et al., 2008; Pei et al., 2007).

Lee defined $\mathrm{OD}_{600 \mathrm{~nm}}>1$ as a strong biofilm-forming strain, $0.5<\mathrm{OD}_{600 \mathrm{~nm}}<1$ as a moderate biofilm-forming strain, and $\mathrm{OD}_{600 \mathrm{~nm}}<0.5$ as a weak biofilm strain (Lee et al., 2012). According to his definition, the biofilm formation ability of all 33 isolates were weaker than S. Typhymurium ATCC 14028 at $28^{\circ} \mathrm{C}$. There were two C. sakazakii isolates, codex YL32 and YL33, which had strong biofilm formation ability. PFGE showed that both isolates cultured from the same source (swabs of staff's sole in Factory A); once these isolates are found to persist in the workshop, they will cause a potential long term threat such as PIF contamination. There were eight moderate biofilm-forming strains, including YL15, YL21, and YL23 which belonged to pulsotype C3 with 100\% similarity and isolated from disk sedimentation of rear packaging room and soil sample. And YL16, YL19, YL20, YL25, and YL26 with moderate biofilm formation ability belonged to $\mathrm{C} 8$ and came from lactose powders. These isolates could cause persistent contamination on the surface of productive facilities and affect the safety of end products. Two C. malonaticus isolates were strong biofilm-forming strains at $37^{\circ} \mathrm{C}$ and moderate at $28^{\circ} \mathrm{C}$. The National Institutes of Health (NIH) of America announced that over $80 \%$ of microbial infections were found involved in biofilm formation (Römling and Balsalobre, 2012). Cronobacter could form biofilm on different materials such as silicon, latex, polycarbonate, stainless steel, glass, and polyvinyl chloride (Choi et al., 2014). Cells of Cronobacter in biofilm could survive for several weeks under dry conditions and resistant to 


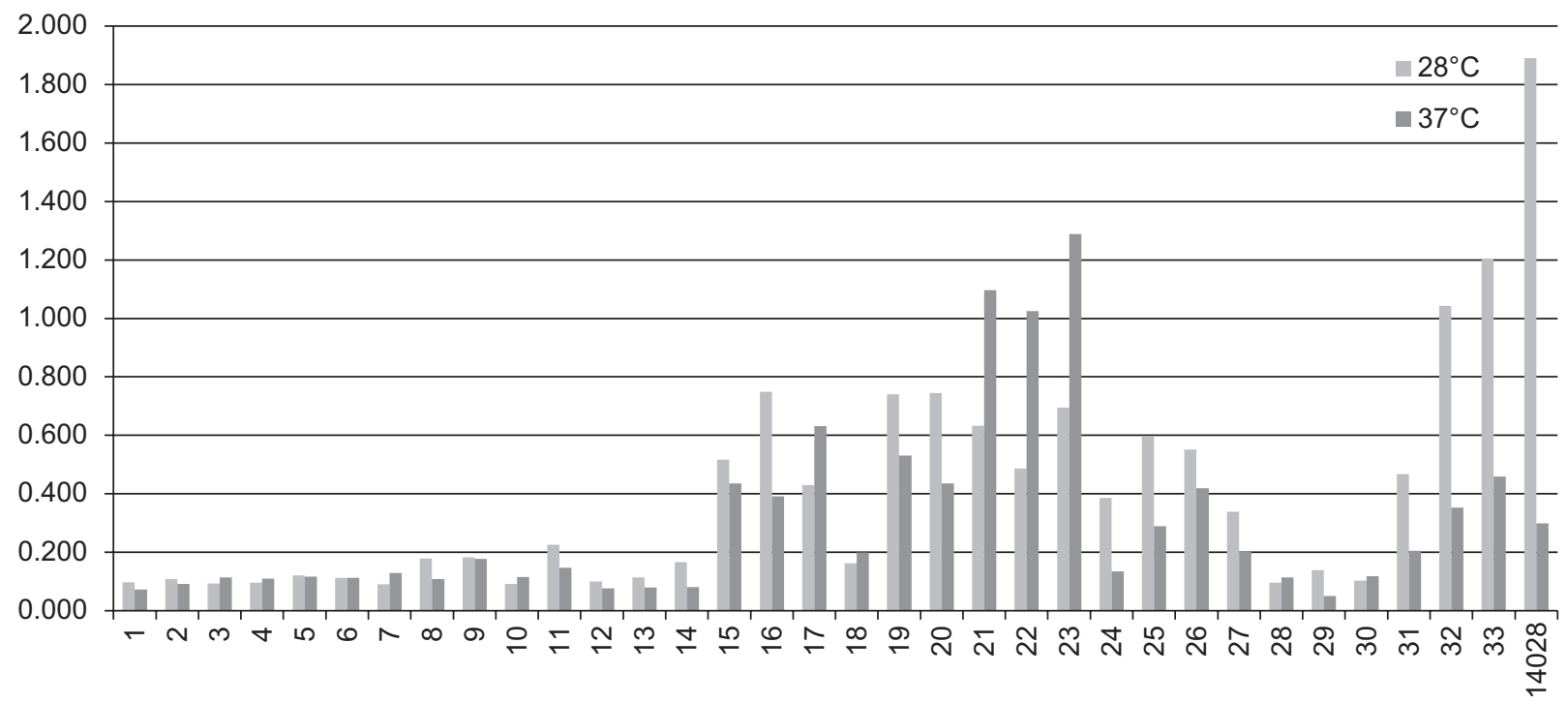

Figure 2 Comparison of biofilm formation by 33 Cronobacter isolates at $28^{\circ} \mathrm{C}$ and $37^{\circ} \mathrm{C}$.

osmotic pressure (Dancer et al., 2009). Biofilm has a great impact on PIF industry, persistent strains with biofilm formation ability could store on the surface of packaging materials and processing equipment for a long time, and resistant to common cleaning agents, disinfection and sterilization methods, and cause a long term and persistent contamination in production environment. A strict regulatory strategy for PIF manufactures including successive monitoring for environment, raw ingredients, semi and end products, particular disinfection procedures are needed. Hazard analysis and critical point (HACCP) systems could be the effective control measures and decrease the risk of Cronobacter contamination along the entire production chain.

\section{Conclusion}

Totally, 33 isolates of Cronobacter were isolated form raw ingredients, PIF processing environment, and workers' sole from two PIF processing factories in Shanxi province, China between July and November 2016. C. sakazakii was found to be the predominant species in different sources of our surveillance. The results suggest that two factories exited multi-source contamination of Cronobacter, especially in the PIF processing environment. C. sakazakii and C. malonaticus could form biofilm at either $28^{\circ} \mathrm{C}$ or $37^{\circ} \mathrm{C}$, with strong biofilm formation ability at $37^{\circ} \mathrm{C}$ for $\mathrm{C}$. malonaticus. The data obtained in the present study would provide the scientific basis for prevention and control measures of PIF contamination by Cronobacter during manufacturing. It is necessary to minimize the contamination of this bacterium from different sources and reduce the risk of infants being exposed to Cronobacter via PIF.

\section{Acknowledgements}

This study was funded by the National Key Research and Development Program of China (2018YFC1604303). URL: http://www.most.gov.cn/

\section{Reference}

Chen, Z., Ren, L. and Ma, L., 2011. Analysis on the antimicrobial susceptibility testing of Enterobacter sakazakii isolated from Xinjiang. Modern Preventive Medicine 38: 3539-3541.

Chenu, J.W. and Cox, J.M., 2009. Cronobacter ('Enterbacter sakazakii'): current status and future prospects. Letters in Applied Microbiology 49: 153-159. https://doi.org/10.1111/j. 1472-765X.2009.02651.X

Choi, Y., Kim, S., Hwang, H., Kim, K.P. and Ryu, S., 2014. Plasmidencoded mcp is involved in virulence, motility, and biofilm formation of Cronobacter sakazakii ATCC 29544. Infection and Immunity 83: 197-204. https://doi.org/10.1128/iai.02633-14.

CLSI M100S, 2016. Performance Standards for Antimicrobial Susceptibility Testing, 26th Edition. Clinical and Laboratory Standards Institute.

Dancer, G.I., Mah, J.H., Rhee, M.S., Hwang, I.G. and Kang, D.H., 2009. Resistance of Enterbacter sakazakii (Cronobacter spp.) to environmental stresses. Journal of Applied Microbiology 107: 1606-1614. https://doi.org/10.1111/j.1365-2672.2009.04347.x

Drapala, K.P., Mulvihill, D.M. and O'Mahony, J.A., 2018. Improving the oxidative stability of model whey protein hydrolysatebased infant formula emulsions with lecithin. International Journal of Dairy Technology 71: 966-974. https://doi. org/10.1111/1471-0307.12538

Fei, P., Man, C., Lou, B., Forsythe, S.J., Chai, Y., Li, R., et al., 2015. Genotyping and source tracking of Cronobacter sakazakii and C. malonaticus isolates from powdered infant formula 
and an infant formula production factory in china. Applied and Environmental Microbiology 81: 5430-5439. https://doi. org/10.1128/AEM.01390-15

Fei, P., Jiang, Y., Jiang, Y., Yuan, X., Yang, T., Chen, J., et al., 2017. Prevalence, molecular characterization, and antibiotic susceptibility of Cronobacter sakazakii isolates from powdered infant formula collected from Chinese retail markets. Frontiers in Microbiology 8: 2026. https://doi.org/10.3389/fmicb.2017.02026

Forsythe, S.J., 2018. Updates on the Cronobacter Genus. Annual Review of Food Science and Technology 9: 23-44. https://doi. org/10.1146/annurev-food-030117-012246

Friedemann, M., 2008. Enterobacter sakazakii in powdered infant formula. Bundesgesundheitsbla 51: 664-674. https://doi. org/10.1007/s00103-008-0543-4

Gan, X., Bai, L., Yan, S., Wang, J., Wang, W., Li, Z., et al., 2015. Drug resistant analysis of Cronobacter isolated from infant foods in 2012-2014 in China. Journal of Food Safety and Food Quality 6: 3491-3496.

Gan, X., Dong, Y., Yan, S., Hu, Y., Séamus, F., Wang, J., et al., 2018. Contamination and characterization of multiple pathogens in powdered formula at retail collected between 2014 and 2015 in China. Food Control 87: 40-45. https://doi.org/10.1016/j. foodcont.2017.12.014

GB4789.40, 2016. Cronobacter. National Food Safety Standard Food Microbiological Examination. China.

Gu, M., Han, W. and Yang, J., 2008. Study on antibiotic resistance of Enterobacter sakazakii isolated from imported dairy product. Journal of Inspection Quarterly 21: 14-16. https://doi. org/10.3969/j.issn.1674-5354.2008.01.005

Gurtler, J.B. and Beuchat, L.R., 2007. Survival of Enterobacter sakazakii in powdered infant formula as affected by composition, water activity, and temperature. Journal of Food Protection 70: 1579. https://doi.org/10.1016/j.jfoodeng.2006.05.001

Henry, M. and Fouladkhah, A., 2019. Outbreak history, biofilm formation, and preventive measures for control of Cronobacter sakazakii in infant formula and infant care settings. Microorganisms 7: 77. https://doi.org/10.3390/ microorganisms 7030077

Iversen, C., Lane, M. and Forsythe, S.J., 2004. The growth profile, thermotolerance and biofilm formation of Enterbacter sakazakii grown in infant formula milk. Letters in Applied Microbiology 38: 378-382. https://doi.org/10.1111/j.1472-765X.2004.01507.x

Jaradat, Z.W., Al, M.W., Elbetieha, A., Al, N.A. and Tall, B.D., 2014. Cronobacter spp.- opportunistic foodborne pathogens. A review of their virulence and environmental-adaptive traits. Journal of Medical Microbiology 63: 1023-1037. https://doi.org/10.1099/ jmm.0.073742-0

Kalyantanda, G., Shumyak, L. and Archibald, L.K., 2015. Cronobacter species contamination of powdered infant formula and the implications for neonatal health. Frontiers in Pediatrics 3: 56. https://doi.org/10.3389/fped.2015.00056

Lee, Y.D., Park, J.H. and Chang, H.I., 2012. Detection, antibiotic susceptibility and biofilm formation of Cronobacter spp. from various foods in Korea. Food Control 24: 225-230. https://doi. org/10.1016/j.foodcont.2011.09.023
Lehner, A., Fricker-Feer, C. and Stephan, R., 2012. Identification of the recently described Cronobacter condiment by an rpoB-genebased PCR system. Journal of Medical Microbiology 61: 10341035. https://doi.org/10.1099/jmm.0.042903-0

Ling, N., Li, C., Zhang, J., Wu, Q., Zeng, H., He, W., et al., 2018. Prevalence and molecular and antimicrobial characteristics of Cronobacter spp. isolated from raw vegetables in China. Frontiers in Microbiology 9: 1149. https://doi.org/10.3389/ fmicb.2018.01149

Liu, Y., Gao, Q., Zhang, X., Hou, Y., Yang, J. and Huang, X., 2006. PCR and oligonucleotide array for detection of Enterobacter sakazakii in infant formula. Molecular and Cellular Probes 20: 11-17. https://doi.org/10.1016/j.mcp.2005.08.004

Martins, M., Mccusker, M.P., Mccabe, E.M., O'Leary, D., Duffy, G. and Séamus, F., 2013. Evidence of metabolic switching and implications for food safety from the phenome(s) of Salmonella enterica serovar typhimurium dt104 cultured at selected points across the pork production food chain. Applied and Environmental Microbiology 79: 5437-5449. https://doi. org/10.1128/AEM.01041-13

Pei, X., Guo, Y., Xu, J. and Liu, X., 2007. Antibiotic susceptibility of Enterobacter sakazakii isolated from powdered formula for infant and young children. Journal of Hygiene Research 36: 63-65. https://doi.org/10.1016/S1672-6529(07)60007-9

Pires, R.P.S., Cappato, L.P., Guimares, J.T., Rocha, R.S. and Cruz, A.G., 2020. Ohmic heating for infant formula processing: evaluating the effect of different voltage gradient. Journal of Food Engineering 280: 109989. https://doi.org/10.1016/j. jfoodeng.2020.109989

Römling, U. and Balsalobre, C., 2012. Biofilm infections, their resilience to therapy and innovative treatment strategies. Journal of Internal Medicine 272: 541-561. https://doi.org/10.1111/ joim.12004

Stoop, B., Lehner, A., Iversen, C., Fanning, S. and Stephan, R., 2009. Development and evaluation of rpob based pcr systems to differentiate the six proposed species within the genus Cronobacter. International Journal of Food Microbiology 136: 165-168. https://doi.org/10.1016/j.ijfoodmicro.2009.04.023

Tutar, E., Akinci, S.K. and Akyol, I., 2018. Development and application of a new multiplex real-time pcr assay for simultaneous identification of brucella melitensis, Cronobacter sakazakii and Listeria monocytogenes in raw milk and cheese. International Journal of Dairy Technology 71: 629-636. https://doi. org/10.1111/1471-0307.12500

Ueda, S., 2017. The effects of temperature on the growth and heat resistance of Cronobacter spp.. Biocontrol Science 22: 125-129. https://doi.org/10.4265/bio.22.125

Yan, Q., Wang, J., Gangiredla, J., Cao, Y., Martins, M., Gopinath, G.R., et al., 2015. Comparative genotypic and phenotypic analysis of Cronobacter species cultured from four powdered infant formula production facilities: indication of pathoadaptation along the food chain. Applied and Environmental Microbiology 81: 4388-4402. https://doi.org/10.1128/AEM.00359-15 